\title{
Ginsenoside-Rh2 Inhibits Proliferation and Induces Apoptosis of Human Gastric Cancer SGC-7901 Side Population Cells
}

\author{
Jun Qian ${ }^{1 \& *}$, Jing Li ${ }^{1 \&}$, Jian-Guang Jia ${ }^{1}$, Xin Jin ${ }^{1}$, Da-Jun Yu ${ }^{1}$, Chen-Xu Guo ${ }^{1}$, \\ Bo Xie ${ }^{1}$, Li-Yu Qian ${ }^{1}$
}

\begin{abstract}
Objectives: To observed the effects of ginsenoside -Rh2 (GS-Rh2) on proliferation and apoptosis of side population (SP) human gastric cancer SGC-7901 cells. Materials and Methods: SGC-7901 SP and Non-SP cells were sorted by flow cytometry and assessed using the cck-8 method. Expression of apoptosis-related proteins Bax and Bcl-2 of SP before and after the intervention was determined by Western-blotting. Results: It was found that the proliferation of SP was significantly faster than that of NSP $(P<0.05)$. In addition, GS-Rh2 inhibited proliferation of gastric cancer SP cells, induced cell cycle arrest and cell apoptosis, and changed the expression of BAX/Bcl-2 proteins in a time-dependent and concentration-dependent manner $(P<0.05)$. Conclusions: With increase of GS-Rh2 dose, GS-Rh2 gradually inhibit the proliferation of SGC-7901 SP cells, which have high proliferation rate, through G1/G0 phase arrest, followed by apoptosis which involves the up-regulation of Bax and the down-regulation of Bcl-2.
\end{abstract}

Keywords: Gastric cancer - side population cells - ginsenoside -rh2 - proliferation - apoptosis

Asian Pac J Cancer Prev, 17 (4), 1817-1821

\section{Introduction}

Gastric cancer is the most commonly diagnosed gastrointestinal cancer with high recurrence rate, high metastatic rate and resistance to chemotherapeutic drugs (Saricanbaz et al., 2014). Today, the biological characteristics of gastric cancer cells are investigated mainly through studying proliferation (Kato et al., 2012), apoptosis (Akagi et al., 2013), nude mice tumorigenic (Zheng et al., 2010) and protein molecular level of gastric cancer cells (Wang et al., 2014).

Ginseng is one of the commonly used Chinese traditional medicines that showed anti-cancer activity in clinical studies (Nakata H et al., 1998). The research proved that the mainly active ingredients of anti-tumor in ginseng is ginsenosides (Choi S et al., 2011; Tang XP et al., 2013) , through the comparison of various kinds of ginsenoside found that GS-Rh2 has the strongest ability to inhibited the proliferation of cancer cells (Li B et al., 2011).

SP was proved to be a cell subset with low fluorescence as a result of the Hoechst 33342 staining, which is the founding belongs to Goodel et al (Goodell et al., 1996), who used Hoechst 33342 and flow cytometry to stain and sort bone marrow cells in mice. SP can be sorted through ABCG-2 (adenosine triphosphate binding cassette super family $\mathrm{G}$ member-2 of transport protein, $\mathrm{ABCG}$ -
2) because ABCG-2 has the feature of Hoechst 33342 excretion and expresses in high level in SP (Shaharuddin et al., 2014). Recent studies have shown that SP cells have a faster proliferation rate than NSP cells (Kong et al., 2014), so studying the biological characteristics of malignancies from the SP cells is great significance.

The aim of this study was to investigate effects of GS-Rh2 on the proliferation and apoptosis of SP isolated from human gastric cancer SGC-7901 cells.

\section{Materials and Methods}

\section{Cell line}

Human gastric cancer cell line SGC-7901 was purchased from the Chinese Academy of Sciences (Shanghai Cell Bank, Shanghai, China).

\section{Reagents and instruments}

Cell culture medium RPMI-1640 and $0.25 \%$ trypsin were purchased from Hyclone (Logan, UT, USA); Penicillin-Streptomycin, Liquid was purchased from Invitrogen (Carlsbad, CA, USA); fetal bovine serum (FBS) was purchased from Tianhang Biological Technology,(Hangzhou, Zhejiang, China); Hoechst 33342 and verapamil were obtained from Sigma (Saint Louis, MO, USA); GS-Rh2 was purchased from Sigma; the 
CCK-8 reagent was purchased from Beyotime (Nantong, Jiangsu, China); and AV kit and PI were obtained from BD (Franklin Lakes, NJ, USA). Antibodies against BAX and Bcl-2 antibodies were obtained from Boster (Wuhan, Hubei, China) and $\beta$-actin antibody was obtained from Sigma Company; horseradish peroxidase-labeled goat anti-rabbit IgG was purchased from Zhongshan, (Beijing, China); the substrate reagent was purchased from Millipore Company, (Boston, MA, USA). flow cytometers BD FACS ARIAII SORP and BD FACSCalibur were purchased from BD (Franklin Lakes, NJ, USA), electrophoresis apparatus and gel imaging system were obtained from BioTeK Synergy 2 (BioTeK, VT, USA), and power supply and gel imaging system ChemiDox XRS were from Bio-Rad (Hercules, CA, USA).

\section{Flow cytometry and cell sorting}

Cells were digested with $0.25 \%$ trypsin-EDTA, centrifuged at $1,000 \mathrm{rpm}$ for $5 \mathrm{~min}$ at $4{ }^{\circ} \mathrm{C}$, and resuspended in PBS with $2 \%$ FBS. Live cell number was counted at least twice and adjusted to a final cell density of $1 \times 10^{6}$ cells $/ \mathrm{ml}$, incubated at $37^{\circ} \mathrm{C}$ for $120 \mathrm{~min}$ with $5 \mu \mathrm{g} / \mathrm{mL}$ Hoechst 33342, either alone or in combination with $50 \mu \mathrm{mol} / \mathrm{L}$ verapamil $(100 \mathrm{mg} / \mathrm{L})$, centrifuged for $5 \mathrm{~min}$, and resuspended in cold PBS with $2 \% \mathrm{FBS}$ at 1 $\times 10^{6}$ cells $/ \mathrm{ml}$. SP cells were identified and sorted using Hoechst 33342; the signal was collected as follows: blue light, $402-446 \mathrm{~nm}$, and red light, 650-670 nm, SP and NSP cells were separated using a flow cytometer.

\section{Cell Culture}

SGC-7901 human gastric cells were maintained in RPMI-1640 medium containing $100 \mathrm{u} / \mathrm{ml}$ of penicillin, $100 \mathrm{ug} / \mathrm{ml}$ of streptomycin and $10 \% \mathrm{FBS}$, at $37^{\circ} \mathrm{C}$ in a humidified and $5 \% \mathrm{CO}_{2}$ atmosphere.

\section{Cell Sorting}

The cells were harvested by detachment with $0.25 \%$ trypsin-EDTA and resuspended in PBS with $2 \%$ FBS, added hoechst 33342 (final concentration is $5 \mathrm{ug} / \mathrm{ml}$ ) into the cell suspension, and control group was supplemented with $10 \mathrm{ul} / \mathrm{ml}$ verapamil additionally. Incubated all the cells at $37^{\circ} \mathrm{C}$ in $5 \% \mathrm{CO}_{2}$ atmosphere for $90 \mathrm{~min}$. Cells were collected and then resuspended in ice-cold PBS with $2 \%$ FBS at $1 \times 10^{6}$ cells $/ \mathrm{ml}$. Then SP and NSP cells were identified and sorted by a flow cytometry, and the signal was collected as follows: blue light, $402-446 \mathrm{~nm}$; red light, $650-670 \mathrm{~nm}$.

\section{Cell proliferation assay}

Cells were cultured at $37^{\circ} \mathrm{C}$ in a humidified and $5 \%$ $\mathrm{CO}_{2}$ atmosphere. Cell proliferation was analyzed as detailed in CCK-8 kit instructions. All tests were done in triplicate and the experiments were repeated three times independently. The values were converted to cell numbers using the standard curve. The data were presented as \pm standard error $(\overline{\mathrm{x}} \pm \mathrm{s})$.

Cell Cycle analysis

Cells were collected and washed with PBS twice, and resuspended in $1 \mathrm{ml}$ of cold $70 \%$ ethanol, incubated at -20 ${ }^{\circ} \mathrm{C}$ overnight. The cells were pelleted by centrifugation and washed by PBS, resuspended in $0.5 \mathrm{ml} \mathrm{PBS}$ with $50 \mathrm{ug} /$ $\mathrm{ml}$ of PI, and incubated in dark at $37^{\circ} \mathrm{C}$ for $30 \mathrm{~min}$, then cell cycle progression was analyzed by flow cytometry.

\section{Apoptosis assay}

The cells were collected and washed with PBS twice, then the cells were resuspended in $250 \mathrm{ul}$ binding buffer, $3 \mathrm{ul} \mathrm{AV}$ and $3 \mathrm{ul} \mathrm{PI}$, incubated in dark for $15 \mathrm{~min}$, then cell apoptosis rate was analyzed through flow cytometry.

\section{Protein analysis}

Cell total protein was extracted by lysates (PMSF: $\mathrm{RIPA}=1: 100)$. Protein concentration was adjusted to $60 \mathrm{ug} /$ ul by RIPA. Protein was boiled at $99^{\circ} \mathrm{C}$ for $5 \mathrm{~min}$, stored at $-80^{\circ} \mathrm{C}$ for use. Proteins were separated by electrophoresis in $12 \%$ of separating Gel and $5 \%$ of stacking gel. Then the protein was transferred onto PVDF membrane. PVDF membrane was blocked with 5\% non-fat milk at room temperature for 1-3 $\mathrm{h}$. The PVDF membrane was incubated in primary antibody solution at $4{ }^{\circ} \mathrm{C}$ overnight. The PVDF membrane was washed by TBST, then the PVDF membrane was incubated in secondary antibody solution at $4{ }^{\circ} \mathrm{C}$ for $1 \mathrm{~h}$. Protein bands exposure were performed using chromogenic substrate. The protein bands were analyzed by densitometry using Quantity One software (Bio-Rad). $\beta$-actin was used as internal control.

\section{Statistical analysis}

All experiments were repeated 3 times independently, and the data were presented as \pm standard error $( \pm \mathrm{s})$. Statistical significance $(p<0.05)$ was assessed by the analysis of variance (ANOVA) followed by Student's t-test.

\section{Results}

Ratio of SP in SGC-7901 Cell Line

The ratio of SP in SGC-7901 cell line was $(3.53 \pm 0.79) \%$, Meanwhile, the ratio of SP in control group (Verapamil group) was $0.1 \%$ (Figure 1).

\section{Proliferation of SP and NSP in SGC-7901 Cell Line}

Compared with NSP, the proliferation ability of SP was significantly higher $(p<0.05)$. (Figure 2$)$.

\section{Proliferation of SP cells treated with GS-Rh2}

After treated by the different dose of GS-Rh2 or normal saline respectively, cell proliferation of SGC-7901 SP were determined. As can be see in Figure 3, compared with the normal saline group (control group) at corresponding time point, different dose of GS-Rh2 treatments inhibited cell proliferation in a time-dependent and concentrationdependent manner $(p<0.05)$. (Figure 3$)$.

\section{Cell cycle of SP treated with GS-Rh2}

As can be seen in Figure 4 and Table 1, The treatment with GS-Rh2 caused significant changes in SP cell cycle compared to the untreated control group. The percentage of G0/G1 cells increased, whereas that of the cells in the S and $\mathrm{G} 2 / \mathrm{M}$ phases decreased. The effect showed a marked dependence on GS-Rh2 concentration $(p<0.05)$ and the 
Ginsenoside -Rh2 Inhibits Proliferation and Induces Apoptosis of Human Gastric Cancer SGC-7901 Side Population Cells

Table 1. Effect of GS- Rh2 on SGC-7901GC SP Cell Cycle after 24-h and 48-h Treatment $(n=3, \bar{x} \pm s, \%)$

\begin{tabular}{ccccccc}
\hline \multirow{2}{*}{ Group } & \multicolumn{3}{c}{ 24-h Cell cycle (\%) } & \multicolumn{3}{c}{ 48-h Cell cycle (\%) } \\
\cline { 2 - 7 } & G1/G0 & $\mathrm{S}$ & $\mathrm{G} 2 / \mathrm{M}$ & $\mathrm{G} 1 / \mathrm{G} 0$ & $\mathrm{~S}$ & $\mathrm{G} 2 / \mathrm{M}$ \\
\hline Control & $52.4 \pm 1.8$ & $24.7 \pm 1.4$ & $23.2 \pm 1.9$ & $48.6 \pm 2.3$ & $26.0 \pm 1.3$ & $25.3 \pm 1.2$ \\
$5 \mathrm{ug} / \mathrm{ml}$ & $59.3 \pm 1.1$ & $22.8 \pm 1.0$ & $17.9 \pm 1.6^{*}$ & $63.8 \pm 1.4^{*}$ & $20.1 \pm 1.0^{*}$ & $16.1 \pm 0.7^{*}$ \\
$10 \mathrm{ug} / \mathrm{ml}$ & $62.4 \pm 1.2^{*}$ & $21.2 \pm 1.2^{*}$ & $16.4 \pm 1.0^{*}$ & $80.3 \pm 1.3^{* \#}$ & $9.9 \pm 1.6^{* \#}$ & $9.9 \pm 0.8^{* \#}$ \\
$20 \mathrm{ug} / \mathrm{ml}$ & $75.0 \pm 1.1^{*}$ & $8.8 \pm 0.8^{*}$ & $16.2 \pm 0.9^{*}$ & $88.7 \pm 1.7^{* \#}$ & $4.5 \pm 1.2^{* *}$ & $6.8 \pm 1.1^{* \#}$ \\
\hline
\end{tabular}

${ }^{*} p<0.05$ compared with corresponding cell cycle phase in control group; ${ }^{*} p<0.05$ in same serum group, cell cycle phases in $48 \mathrm{~h}$ group show significant difference than corresponding cell cycle phases in $24 \mathrm{~h}$ group

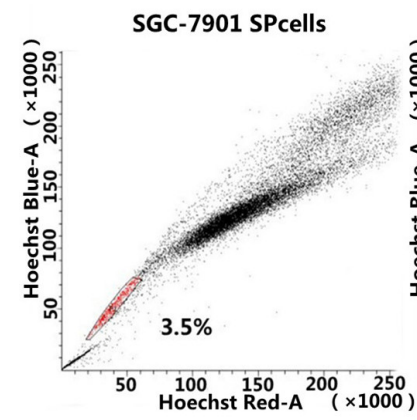

A

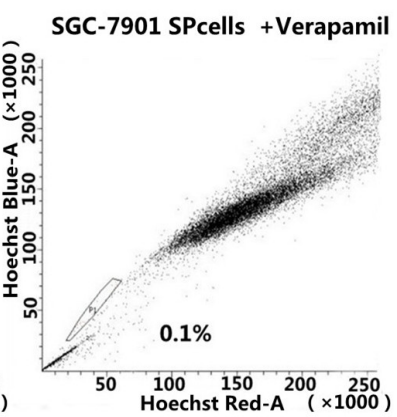

B

Figure 1.SP detection graph of SGC-7901 cell line by flow cytometry. The SP in SGC-7901 were sorted as detailed in "Cell sorting". The figures shown are representative of three independent experiments. A. SP detection graph without treatment of Verapammy; B. SP detection graph of Verapammy group

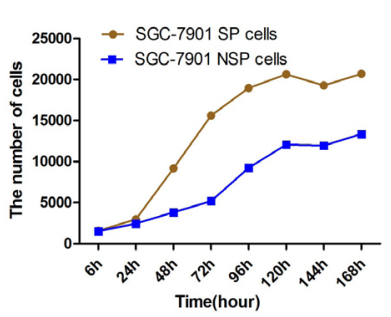

A

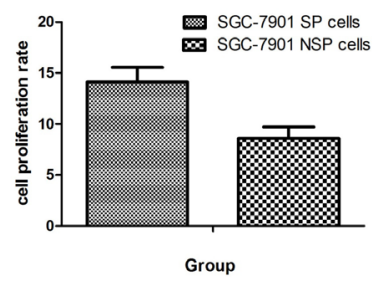

B

Figure 2. The Cell Proliferation of SGC-7901 SP and NSP. SP and NSP were seeded into 96-well plates at $1 \times 10^{3}$ cells per well and treated with 100ul RPMI1640 supplemented with $10 \%$ fetal bovine serum. Cell proliferation was analyzed after treatments of $6 \mathrm{~h}, 24 \mathrm{~h}, 48 \mathrm{~h}, 72 \mathrm{~h}, 96 \mathrm{~h}, 120 \mathrm{~h}, 144 \mathrm{~h}$, and $168 \mathrm{~h}$ as detailed in "Cell proliferation assay". A. The number of SP and NSP of SGC-7901 after cultured for 168 hours; B. After cultured for 168 hours, the cell proliferation rate of SP and NSP of SGC-7901, cell proliferation rate were determined using following formula. Cell proliferation rate=The number of cells at $168 \mathrm{~h} /$ The number of cells at $6 \mathrm{~h}$

Table 2. Apoptosis Rates of SGC-7901SP after Treated with Different dose GS-Rh2 (n=3, $\bar{x} \pm s, \%)$

\begin{tabular}{lcc}
\hline Group & 24-h Apoptosis rates & 48-h Apoptosis rates \\
\hline Control & $4.5 \pm 0.8$ & $5.5 \pm 0.4$ \\
$5 \mathrm{ug} / \mathrm{ml}$ & $6.3 \pm 0.4$ & $8.9 \pm 2.3$ \\
$10 \mathrm{ug} / \mathrm{ml}$ & $9.4 \pm 0.9 *$ & $19.5 \pm 2.7 * \#$ \\
$20 \mathrm{ug} / \mathrm{ml}$ & $17.5 \pm 1.6^{*}$ & $39.4 \pm 1.0 * \#$ \\
\hline
\end{tabular}

$* p<0.05$ compared with corresponding control group. $\# p<0.05$ in same dose group, cell apoptosis rates in $48 \mathrm{~h}$ group show significant difference than corresponding cell apoptosis rates in $24 \mathrm{~h}$ group.
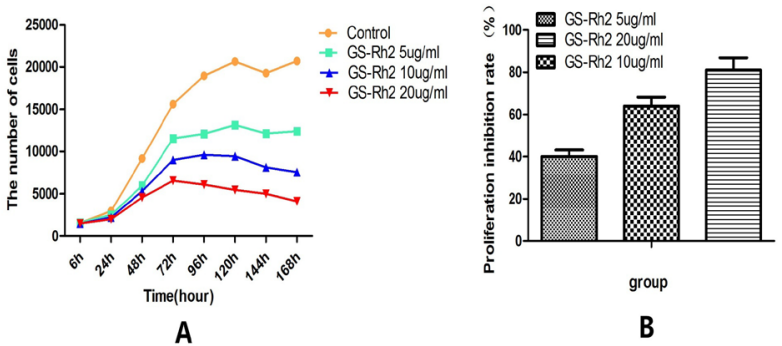

Figure 3. The effects of Different dose of GS-Rh2 Intervention on Cell Proliferation of SGC-7901 SP. SP were seeded into 96 -well plates at $1 \times 10^{3}$ cells per well and were treated by cell culture medium containing GS-Rh2 5ug/ $\mathrm{ml}$, GS-Rh2 $10 \mathrm{ug} / \mathrm{ml}$ or GS-Rh2 $20 \mathrm{ug} / \mathrm{ml}$ or normal saline (control) respectively. Cell proliferation was analyzed after treatments of 6 h, 24 h, 48 h, 72 h, 96 h, 120 h, 144 h, and 168 $\mathrm{h}$ as detailed in "Cell proliferation assay". A. The number of SGC-7901 SP after intervention (GS-Rh2 5ug/ml, GS-Rh2 10ug/ $\mathrm{ml}$ or GS-Rh2 20ug/ml) for 168 hours; B. After intervention for 168 hours, proliferation inhibition rates of SGC-7901 SP, proliferation inhibition rates were determined using following formula. Proliferation inhibition rate $(\%)=(1$-Drug group $/$ Control group) $\times 100 \%$

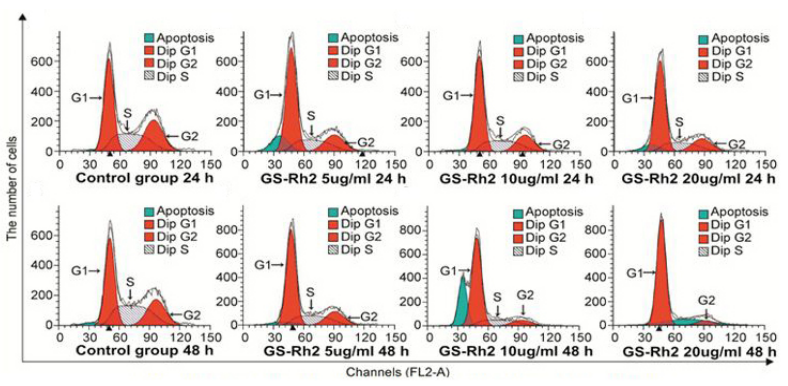

Figure 4. The Changes in the Cell Cycle After Treated Different dose of GS-Rh2 $(5 \mathrm{ug} / \mathrm{ml}, 10 \mathrm{ug} / \mathrm{ml}$ or $20 \mathrm{ug} /$ ml). SGC-7901 SP were all randomly divided into 4 groups, then $2 \mathrm{ml}$ of SP cells suspension $\left(5 \times 10^{5}\right.$ cells $\left./ \mathrm{ml}\right)$ were seeded into 60-mm Petri dish respectively, and were treated by cell culture medium containing GS-Rh2 $5 \mathrm{ug} / \mathrm{ml}$, GS-Rh2 $10 \mathrm{ug} / \mathrm{ml}$ or GS$\mathrm{Rh} 220 \mathrm{ug} / \mathrm{ml}$ or normal saline (control) respectively. After 24 $\mathrm{h}$ and $48 \mathrm{~h}$ of treatment, cell cycle progression was analyzed by flow cytometry as detailed in "Cell cycle analysis"

time of treatment: it was more obvious at $48 \mathrm{~h}$ than at $24 \mathrm{~h}(p<0.05)$. Based on these results, we can conclude that GS-Rh2 restricts SP cell cycle to G0/G1 phase in a time-dependent and dose-dependent manner. (Figure 4 and Table 1).

Apoptosis of SP treated with GS-Rh2

As can be seen in Figure 5 and Table 2, after the treatment with GS-Rh2, SGC-7901 SP demonstrated a significant increase in apoptosis, which depended on 
Table 3. Bax /Bcl-2protein expression in SGC-7901SP treated with different dose GS-Rh2 $(n=3, \pm s)$

\begin{tabular}{ccccc}
\hline \multirow{2}{*}{ Group } & \multicolumn{2}{c}{ Bax } & \multicolumn{2}{c}{ Bcl-2 } \\
\cline { 2 - 5 } & $24-\mathrm{h}$ & $0.28 \pm 0.03$ & $24 \mathrm{~h}$ & $48 \mathrm{~h}$ \\
\hline Control & $0.29 \pm 0.01$ & $0.35 \pm 0.01^{*}$ & $1.27 \pm 0.02$ & $1.30 \pm 0.03$ \\
$5 \mathrm{ug} / \mathrm{ml}$ & $0.32 \pm 0.02$ & $0.77 \pm 0.01^{*} \#$ & $0.97 \pm 0.03^{*}$ & $1.11 \pm 0.02$ \\
$10 \mathrm{ug} / \mathrm{ml}$ & $0.38 \pm 0.02^{*}$ & $0.99 \pm 0.01^{*} \#$ & $0.50 \pm 0.01^{*}$ & $0.53 \pm 0.02^{*} \#$ \\
$20 \mathrm{ug} / \mathrm{ml}$ & $0.49 \pm 0.03^{*}$ & & $0.19 \pm 0.01^{*} \#$ \\
\hline
\end{tabular}

$* p<0.05$ compared with corresponding control group. \# $p<0.05$ in same dose group, Bax /Bcl-2 protein expression in $48 \mathrm{~h}$ group show significant difference than corresponding $\mathrm{Bax} / \mathrm{Bcl}-2$ protein expression in $24 \mathrm{~h}$ group.
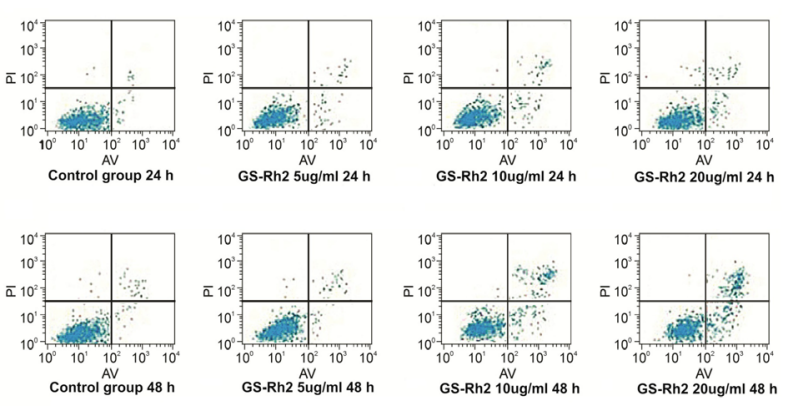

Figure 5. Different dose $(5 \mathrm{ug} / \mathrm{ml}, 10 \mathrm{ug} / \mathrm{ml}$ or $20 \mathrm{ug} / \mathrm{ml})$ Induced Apoptosis in SGC-7901 SP. SP were all randomly divided into 4 groups, then $2 \mathrm{ml}$ of SP cells suspension $\left(5 \times 10^{5}\right.$ cells $/ \mathrm{ml}$ ) were seeded into $60-\mathrm{mm}$ Petri dish respectively, and were treated by culture medium containing GS-Rh2 $5 \mathrm{ug} / \mathrm{ml}$, GS-Rh2 $10 \mathrm{ug} / \mathrm{ml}$ or GS-Rh2 $20 \mathrm{ug} / \mathrm{ml}$ or normal saline (control) respectively. After $24 \mathrm{~h}$ and $48 \mathrm{~h}$ of treatment, cell apoptosis rates were analyzed through flow cytometry as detailed in "Apoptosis assay".
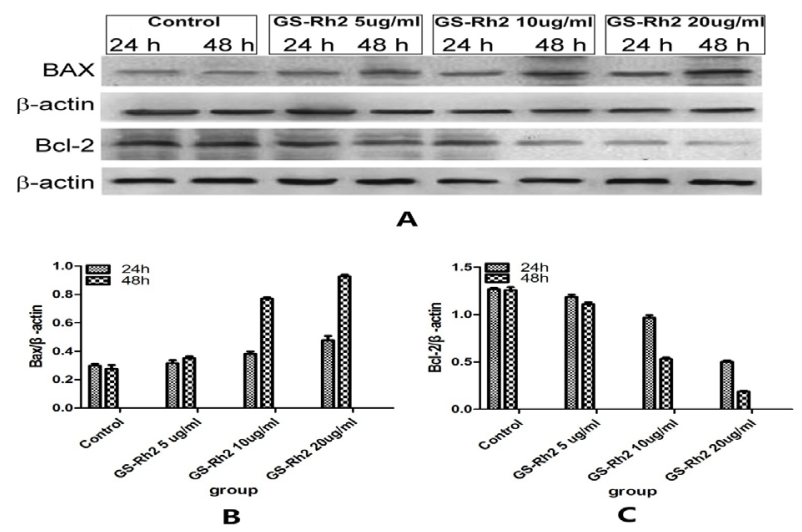

Figure 6. Bax/Bcl-2 Protein Expression in SGC-7901 SP after Treated with Different dose of GS-Rh2 (5ug/ $\mathrm{ml}, 10 \mathrm{ug} / \mathrm{ml}$ or $20 \mathrm{ug} / \mathrm{ml})$. SP were all randomly divided into 4 groups, then SP were seeded into cell culture flasks respectively, and were treated by culture medium containing GS-Rh $25 \mathrm{ug} / \mathrm{ml}$, GS-Rh2 $10 \mathrm{ug} / \mathrm{ml}$ or GS-Rh2 $20 \mathrm{ug} / \mathrm{ml}$ or normal saline (control) respectively. After $24 \mathrm{~h}$ and $48 \mathrm{~h}$ of treatment, Bax/Bcl-2 was analyzed as detailed in "Protein analysis". A. western blot for $\mathrm{Bax} / \mathrm{Bcl}-2$ protein expression after treated with different dose of GS-Rh2; B. The change of Bax protein expression in SGC-7901 $\mathrm{SP} c$ after treated with different dose of GS-Rh2; C. The change of Bcl-2 protein expression in SGC-7901 SP after treated with different dose of GS-Rh2

GS-Rh2 dose $(p<0.05)$ as well as treatment time $(p<0.05)$. These data indicate that GS-Rh2 can effectively induce apoptosis of gastric cancer SGC-7901 SP in a time- dependent and dose-dependent manner. (Figure 5 and Table 2).

$B A X$ and Bcl-2 protein expression in SP treated with GS-Rh2

Based on above results, we investigated the effects of different dose of GS-Rh2 ( $5 \mathrm{ug} / \mathrm{ml}, 10 \mathrm{ug} / \mathrm{ml}$ or $20 \mathrm{ug} / \mathrm{ml})$ on regulators of apoptosis (main inhibitor or promoter ) as molecular targets for the apoptotic death of SGC-7901 SP. Accordingly, we focus our attention on the effects of different dose of GS-Rh2 (5ug/ml, 10ug/ml or $20 \mathrm{ug} / \mathrm{ml})$ on pro-apoptotic protein Bax and Bcl-2 of SGC-7901 SP line because the protein play a key role in cell apoptosis. As shown in Figure 6 and Table 3, treatment of SGC-7901 SP with different dose of GS-Rh2 (5ug/ml, 10ug/ml or 20ug/ $\mathrm{ml}$ ) resulted in increased expression of Bax and inhibited the expression of Bcl-2 in a time-dependent and dosedependent manner. $(p<0.05)$. ( Figure 6 and Table 3 ).

\section{Discussion}

Gastric cancer is one of the world's most deadly malignancies, and effective treatment has been the focus of medical research for many years. As a subtype of cells, SP have a faster proliferation rate than NSP, so SP may play a crucial role in tumor progression

Nowadays, the effects of using Ginseng to against cancer are increasingly discussed in the reports ( Qian et al., 2015). In the present work, SP of SGC-7901 cell line, which in our research had determined that there is a faster proliferation rate than NSP, and GS-Rh2, which extract from Ginseng , are employed as research object.

Firstly, the effects of different dose of GS-Rh2 (5ug/ $\mathrm{ml}, 10 \mathrm{ug} / \mathrm{ml}$ or $20 \mathrm{ug} / \mathrm{ml}$ ) on proliferation of SGC-7901 $\mathrm{SP}$ were assessed. From the experimental results, we found that the proliferation of SP were inhibited in a time-dependent and concentration-dependent manner .

We next detected the effects of different dose of GS-Rh2 on cell cycle of SGC-7901 SP. It is found that treatment of SP cells with different dose of GS-Rh2 result in G1/G0 arrest in cell cycle progression of SP followed by apoptosis in a time-dependent and concentrationdependent manner. It was confirmed by subsequent apoptosis rate test.

In order to further investigate apoptosis induction effect of different dose of GS-Rh2 on SGC-7901 SP, Bax and $\mathrm{Bcl}-2$ were selected as the apoptotic cell death studies in the research, because they are the major, possibly causative apoptotic and anti-apoptotic indicators of the multifactorial mechanisms of uncontrolled gastric cancer 
growth respectively. Apparently, the results showed that different dose of GS-Rh2 induced the activity of proapoptotic protein Bax and inhibited anti-apoptotic protein Bcl-2 in a time-dependent and concentration-dependent manner in SP.

Based on the findings, it is easy to conclude that: GSRh2 can inhibit the proliferation of SP of SGC-7901 cell line followed by apoptosis which is partly mediated via promoting Bax but inhibiting Bcl-2 in a time-dependent and concentration-dependent manner.

The experiment did indicate that treatment of SGC7901 SP with different dose of GS-Rh2 can Inhibit proliferation and induced apoptosis with prolonged treatment, meanwhile, and the dose of GS-Rh2 is a reliable index for effect evaluation.

\section{Acknowledgements}

This research was funded by the National Natural Science Foundation of China (No. 8117386).

\section{References}

Akagi H, Higuchi H, Sumimoto H, et al (2013). Suppression of myeloid cell leukemia-1 (Mcl-1) enhances chemotherapyassociated apoptosis in gastric cancer cells. Gastric Cancer, 16, 100-10.

Choi S, Oh JY and Kim SJ (2011). Ginsenoside Rh2 induces Bcl-2 family proteins-mediated apoptosis in vitro and in xenografts in vivo models. $J$ Cell Biochem, 112, 330-40.

Goodell MA, Brose K, Paradis G, et al (1996). Isolation and functional properties of murine hematopoietic stem cells that are replicating in vivo. $J$ Exp Med, 183, 1797-806.

Kato K, Gong J, Iwama H, et al (2012). The antidiabetic drug metformin inhibits gastric cancer cell proliferation in vitro and in vivo. Mol Cancer Ther, 11, 549-60.

Kong X, Ma MZ, Zhang Y, et al (2014). Differentiation therapy: sesamin as an effective agent in targeting cancer stem-like side population cells of human gallbladder carcinoma. $B M C$ Complement Altern Med, 14, 254.

Li B, Zhao J, Wang CZ, et al (2011). Ginsenoside Rh2 induces apoptosis and paraptosis-like cell death in colorectal cancer cells through activation of p53. Cancer Letters, 301, 185-92.

Nakata H, Kikuchi Y, Tode T, et al (1998). Inhibitory effects of ginsenoside $\mathrm{Rh} 2$ on tumor growth in nude mice bearing human ovarian cancer cells. Jpn J Cancer Re, 89, 733-40.

Qian J, Xie H, Guo, CX, et al (2015). Sijunzi decoction demolition parties inhibit proliferation and induce apoptosis of human gastric cancer BGC-823 side population. Afr J Tradit Complement Altern Med, 12, 77-89.

Saricanbaz I, Karahacioglu E, Ekinci O, et al (2014). Prognostic Significance of Expression of CD133 and Ki-67 in Gastric Cancer. Asian Pac J Cancer Prev, 15, 8215-9.

Shaharuddin B, Harvey I, Ahmad S, et al (2014). Characterisation of human limbal side population cells isolated using an optimised protocol from an immortalised epithelial cell line and primary limbal cultures. Stem Cell Rev, 10, 240-50.

Tang XP, Tang GD, Fang CY, et al (2013). Effects of ginsenoside $\mathrm{Rh} 2$ on growth and migration of pancreatic cancer cells. World J Gastroenterol, 19, 1582-92.

Wang YX, Cai H, Jiang G, et al (2014). Silibinin inhibits proliferation, induces apoptosis and causes cell cycle arrest in human gastric cancer MGC803 cells via STAT3 pathway inhibition. Asian Pac J Cancer Prev, 15, 6791-8.

Zheng T, Meng X, Wang JB, et al (2010). PTEN-and p53- mediated apoptosis and cell cycle arrest by FTY720 in gastric cancer cells and nude mice. J Cell Biochem, 111, 218-28. 